\title{
Breastfeeding in COVID-19: A Pragmatic Approach
}

\author{
Yvonne Peng Mei Ng, MBBS, MRCP, IBCLC ${ }^{1,2} \quad$ Yi Fen Low ${ }^{3} \quad$ Xin Lei Goh ${ }^{3}$ Doris Fok, FILCA \\ Zubair Amin, MBBS, MHPE 1,2
}

${ }^{1}$ Department of Neonatology, Khoo Teck Puat-National University Children's Medical Institute, National University Health System, Singapore

2 Department of Paediatrics, Yong Loo Lin School of Medicine, National University of Singapore, Singapore

${ }^{3}$ Yong Loo Lin School of Medicine, National University of Singapore, Singapore

${ }^{4}$ Department of Obstetrics and Gynecology, Yong Loo Lin School of Medicine, National University of Singapore, Singapore

Am J Perinatol 2020;37:1377-1384.

\author{
Address for correspondence Yvonne Peng Mei Ng, MBBS, MRCP, \\ IBCLC, Department of Neonatology, Khoo Teck Puat-National \\ University Children's Medical Institute, National University Hospital, \\ 1E Kent Ridge Road, NUHS Tower Block Level 12, Singapore 119228 \\ (e-mail: paeynpm@nus.edu.sg).
}

\begin{abstract}
Keywords

- Breastfeeding

- counseling

- COVID-19

- mother-to-child transmission

- severe acute respiratory syndromecoronavirus-2

The novel coronavirus disease 2019 (COVID-19) pandemic has resulted in changes to perinatal and neonatal care, concentrating on minimizing risks of transmission to the newborn and health care staff while ensuring medical care is not compromised for both mother and infant. Current recommendations on infant care and feeding when mother has COVID-19 ranges from mother-infant separation and avoidance of human milk feeding, to initiation of early skin-to-skin contact and direct breastfeeding. Health care providers fearing risks of severe acute respiratory syndrome-coronavirus-2 (SARS-CoV2) maternal-infant transmission may veer toward restricted breastfeeding practices. We reviewed guidelines and published literature and propose three options for infant feeding depending on various scenarios. Option A involves direct breastfeeding with the infant being cared for by the mother or caregiver. In option $B$, the infant is cared for by another caregiver and receives mother's expressed milk. In the third option, the infant is not breastfed directly and does not receive mother's expressed milk. We recommend joint decision making by parents and the health care team. This decision is also flexible as situation changes. We also provide a framework for counseling mothers on these options using a visual aid and a corresponding structured training program for health care providers. Future research questions are also proposed. We conclude that evidence and knowledge about COVID-19 and breastfeeding are still evolving. Our options can provide a quick and flexible reference guide that can be adapted to local needs.
\end{abstract}

Key Points

- SARS-CoV-2 is unlikely transmitted via human milk.

- A shared decision making on infant feeding is the preferred approach.

- Mothers can safely breastfeed with appropriate infection control measures.

received

July 22,2020

accepted

August 7, 2020

published online

September 8, 2020
Copyright $\odot 2020$ by Thieme Medical Publishers, Inc., 333 Seventh Avenue, New York, NY 10001, USA. Tel: +1(212) 760-0888.
DOI https://doi.org/ 10.1055/s-0040-1716506. ISSN $0735-1631$. 
The novel coronavirus disease 2019 (COVID-19) pandemic is rapidly expanding. Global reports of infection have surpassed 13 million cases as of July $17,2020^{1}$ and pregnant women are unlikely to be spared from infection. With uncertainty of risk in perinatal and postnatal mother-to-child transmission of severe acute respiratory syndrome-coronavirus-2 (SARSCoV-2), a few guidelines on perinatal and newborn care have recommended avoidance of skin-to-skin contact, motherinfant separation, and limited breastfeeding or human milk feeding. ${ }^{2-4}$ Other health authorities advocate temporary mother-infant separation and feeds of expressed mother's milk until mother becomes less infectious to her newborn. ${ }^{5}$ These measures contradict established recommendations of breastfeeding as the ideal source of infant nutrition ${ }^{6}$ and may negatively affect establishment of breastfeeding in the critical early days. ${ }^{7}$

A recent Cochrane review analyzed 14 key questions on care of COVID-19 pregnant mothers and babies based on national clinical practice guidelines of 19 countries. Consensus on care practices was not reached for skin-to-skin contact between mother and baby, separation of well babies from mother after birth and breastfeeding in COVID-19. ${ }^{8}$

The World Health Organization's (WHO) recently updated guidelines recommend that mothers with suspected or confirmed COVID-19 infection should be encouraged to initiate and continue breastfeeding because benefits of breastfeeding substantially outweigh the potential risks of transmission. ${ }^{9}$
Therefore, we still face uncertainties in the optimal management of newborn care and breastfeeding. We propose various options (-Table 1 ) that could be considered for infant feeding, and recommend option $\mathrm{A}$ as the optimal mode for safe and mother-and-baby friendly breastfeeding. ${ }^{9-11}$ In individual cases, based on maternal conditions, and shared decision making between health care providers (HCP) and parents, other options may be considered with its risks and benefits understood.

We believe policymakers and HCP should be provided with an up-to-date review of the range of care recommendations from professional and national bodies (with their pros and cons) to devise pragmatic guidelines locally. Our proposed approach is flexible and supported by an educational program for HCP and counseling process for parents. We also propose several research questions to be explored. We hope this review will serve as a concise reference source to all parties involved in infant feeding.

\section{Biological Properties and Transmission Modes of SARS-CoV-2}

The SARS-CoV-2, which belongs to coronavirus family, is a spherical, lipid-enveloped, and single-stranded RNA virus. ${ }^{12}$ SARS-CoV-2 shares $79 \%$ sequence identity to SARS-CoV-1, the causative agent for SARS and utilizes the same angiotensin-converting enzyme 2 (ACE2) receptor for cell entry. ${ }^{13}$

\begin{tabular}{|c|c|c|c|}
\hline & Option A & Option B & Option C \\
\hline Main points & $\begin{array}{l}\text { - Direct breastfeeding } \\
\text { - Infant cared for by mother } \\
\text { (rooming-in) or HCP/caregiver }\end{array}$ & $\begin{array}{l}\text { - Expressed human milk } \\
\text { - Infant cared for by HCP/caregiver }\end{array}$ & $\begin{array}{l}\text { - No breastfeeding and mother's own } \\
\text { milk is not provided }\end{array}$ \\
\hline $\begin{array}{l}\text { Risks to } \\
\text { breastfeeding }\end{array}$ & - Nil & $\begin{array}{l}\text { - Limited mother-infant contact } \\
\text { - Difficulty in establishing latching } \\
\text { - Strain on healthcare resources }\end{array}$ & $\begin{array}{l}\text { - Limited mother-infant contact } \\
\text { - Difficulty in establishing lactation }\end{array}$ \\
\hline $\begin{array}{l}\text { Examples of } \\
\text { situations }\end{array}$ & $\begin{array}{l}\text { - Mother is asymptomatic but swab } \\
\text { positive } \\
\text { - Infant positive for SARS-CoV-2 } \\
\text { - Established breastfeeding } \\
\text { (infection in the first month } \\
\text { postpartum) }\end{array}$ & $\begin{array}{l}\text { - Mother is symptomatic with need for } \\
\text { respiratory support }\end{array}$ & $\begin{array}{l}\text { - Mother is critically ill } \\
\text { - Parents, informed decision is not to } \\
\text { breastfeed } \\
\text { - Safe milk substitute available } \\
\text { (human donor milk or infant } \\
\text { formula) }\end{array}$ \\
\hline \multicolumn{4}{|c|}{$\begin{array}{l}\text { Specific measures: Infant managed as person under investigation (PUI) for up to } 14 \text { days from maternal last positive swab, with surveillance, and } \\
\text { separated from vulnerable nonimmune persons }\end{array}$} \\
\hline $\begin{array}{l}\text { Disposition of } \\
\text { mother and } \\
\text { infant }\end{array}$ & $\begin{array}{l}\text { - Scenario } 1 \text { : mother-infant rooming in } \\
\text { and cares for infant, or } \\
\text { - Scenario } 2 \text { : safe distancing of } 2 \mathrm{~m} \\
\text { between mother and infant, and in- } \\
\text { fant cared by HCP/caregiver. Con- } \\
\text { sider use of physical barriers (e.g., } \\
\text { curtain/isolette) }\end{array}$ & $\begin{array}{l}\text { - Scenario 1: Safe distancing of } 2 \mathrm{~m} \\
\text { between mother and infant, and in- } \\
\text { fant cared by HCP/caregiver. Con- } \\
\text { sider use of physical barriers (e.g., } \\
\text { curtain/isolette) or } \\
\text { - Scenario 2: Isolation of mother and } \\
\text { infant until mother is no longer } \\
\text { infectious }\end{array}$ & $\begin{array}{l}\text { - Isolation of mother and infant until } \\
\text { mother is no longer infectious }\end{array}$ \\
\hline Infant feeding & $\begin{array}{l}\text { Scenario 1: breastfeeding with IPC } \\
\text { practices } \\
\text { Scenario 2: mother to have contact } \\
\text { with infant only during breastfeeding } \\
\text { and breastfeed with IPC practices }\end{array}$ & $\begin{array}{l}\text { Mother expresses human milk with IPC } \\
\text { practices } \\
\text { - Wears facemask and performs hand } \\
\text { and breast hygiene } \\
\text { - Proper pump cleaning } \\
\text { - Dedicated breast pump }\end{array}$ & $\begin{array}{l}\text { - Support continuity of human milk } \\
\text { production by expressing } \\
\text { - Resume breastfeeding or human } \\
\text { milk feeding at appropriate timing } \\
\text { - Alternative sources: donor human } \\
\text { milk or infant formula }\end{array}$ \\
\hline $\begin{array}{l}\text { Handling of } \\
\text { human milk }\end{array}$ & As routine practice & $\begin{array}{l}\text { Disinfect outer surface of milk } \\
\text { containers }\end{array}$ & $\begin{array}{l}\text { Store or discard (as per joint HCP and } \\
\text { parents' decision) }\end{array}$ \\
\hline
\end{tabular}

Abbreviations: COVID-19, novel coronavirus disease 2019; HCP, health care providers; IPC, Infection Prevention and Control; SARS-CoV-2, severe acute respiratory syndrome-coronavirus- 2 . 
Heat, washing with soap for 20 seconds, 60\% alcohol, and commercial and household cleaning products inactivate SARS-CoV-1 and Middle Eastern respiratory syndrome (MERS) viruses ${ }^{14,15}$ and are presumed to have similar effect on SARS-CoV-2.

The incubation period of SARS-CoV-2 infection is on average 5 to 6 days, and can last up to 14 days. ${ }^{9}$ Some infected persons can be contagious, from 1 to 3 days before symptom onset in the "presymptomatic" period. ${ }^{16}$ The mainstay of transmission of SARS-CoV-2 is by symptomatic people to others through respiratory droplets, by direct contact with infected persons, or by contact with contaminated objects and surfaces. ${ }^{9}$ However, active viral replication drops quickly after the first week and viral particles detected after 11 days of illness may be (or likely to be) no longer viable. ${ }^{17}$ This is consistent with WHO recommendations that symptomatic patients are discontinued from transmission-based precautions 10 days after symptom onset plus at least 3 days without fever and respiratory symptoms, and asymptomatic patients can be deisolated 10 days after testing positive. ${ }^{9}$

There is an ongoing debate regarding the definition and risks of congenital versus intrapartum transmission. Various investigators have tested for presence of SARS-CoV-2 in cord blood, placenta, and neonatal nasopharyngeal swabs at birth, 24 hours, and day 2 onwards to differentiate between congenital and intrapartum transmission. ${ }^{18,20}$ A recent probable congenital COVID-19 case was reported, with the widespread presence of virus on placenta, newborn's nasopharyngeal aspirates, blood, and stool ${ }^{19}$ in a mother with familial neutropenia, gestational diabetes, and a history of frequent bacterial infections. Evidence so far has shown the risk of vertical transmission is low. We recently reported a pooled incidence of SARS-CoV-2 vertical transmission rate of 16 per 1,000 newborns (95\% confidence interval $[\mathrm{CI}]: 3.40-73.11$ ). ${ }^{21}$

However, with uncertainties in the natural history of neonates with COVID-19, newborns born to COVID-19-positive mothers considered persons under investigation (PUI) for infection, or if infection status cannot be determined, are to be placed under surveillance for at least 14 days with infection precautions. ${ }^{5}$

In COVID-19-positive mothers who breastfed, a few newborns subsequently tested positive for SARS-CoV-2 after mothers had skin-to-skin contact and breastfed without face masks. ${ }^{22-24}$ It is imperative to adopt infection control measures (e.g., wearing facemask and hand hygiene) during breastfeeding. There is, however, one reported case of a neonate acquiring COVID-19 despite the mother breastfeeding with a face mask. ${ }^{25}$

Transmission of SARS-CoV-2 via human milk is unlikely. Only three authors have reported SARS-CoV-2 in human milk, ${ }^{19,25,26}$ while larger studies did not. ${ }^{27-29}$ Viability of the SARS-CoV-2 in human milk has not been demonstrated. Additionally, if viable SARS-CoV-2 were present in human milk, temperatures near those used in Holder pasteurization $\left(62.5^{\circ} \mathrm{C}\right.$ for 30 minutes) have been found to inactivate the virus. $^{30}$ This would allay the fears about safety of donor human milk from milk banks. Paradoxically, pasteurization is believed to be counterproductive as it would inactivate other immunological properties of milk that might protect the neonates from SARS-CoV-2 and other pathogens. ${ }^{31}$

Despite absence of direct evidence, there is a speculation that the presence of maternal SARS-CoV-2 immunoglobulin (Ig)-G in newborn blood and other Ig in mother's milk protected a 15-day-old breastfeeding infant from symptomatic SARSCoV-2 infection. ${ }^{25}$ During the SARS epidemic in 2003, a mother infected with SARS-CoV-1 at 19 weeks of gestation had antibodies against the virus in her milk. ${ }^{32}$ High levels of Influenza IgA and neutralizing antibodies were present in human milk following influenza vaccination in pregnant women. ${ }^{33}$ The maximum time taken for Ig to appear in human milk is around 38 days after the onset of influenza infection. ${ }^{34}$ In addition to potential specific antibodies, human milk also contains other immune boosting factors (e.g., probiotics, white blood cells, and lactoferrin) for health benefits of the breastfed neonates. ${ }^{35}$

\section{Guidelines for Breastfeeding in COVID-19}

In general, published guidelines for breastfeeding mirror those for maternal influenza infection, ${ }^{36}$ which encourage breastfeeding, while the mother adopts infection control precautions. This is the position taken by the $\mathrm{WHO}^{9}$ and many national health authorities with few exceptions. ${ }^{2,3}$ The WHO concluded that mothers with suspected or confirmed COVID19 should not be separated from their infants, therefore skinto-skin contact and breastfeeding should be initiated from birth while taking precautions to avoid spreading virus to her infant, primarily through contact with mother's infectious respiratory secretions. The WHO's recommendations on Infection Prevention and Control (IPC) are that mothers with suspected, probable, or confirmed COVID-19 should be counseled about droplet and contact precautions during contact with their infant, which are summarized in -Table 2.

Centers for Disease Control and Prevention $(C D C)^{10}$ and American Academy of Pediatrics (AAP), ${ }^{5}$ in general, advise a more conservative approach by recommending temporary mother-baby separation to minimize risk of postnatal transmission from maternal respiratory secretions and providing expressed human milk fed by a healthy caregiver. However, WHO advices this practice only when mother is too ill to care for her infant. In addition, due to evidence that SARS-CoV-2 remains viable on surfaces for hours to days, ${ }^{15,37}$ if expressed human milk is to be fed, disinfection of the external surfaces of milk containers may be considered ${ }^{10,38}$ to prevent virus transmission to the caregiver or HCP.

The third and the most restrictive approach is taken in China where breastfeeding is still prohibited until mother is confirmed to be SARS-CoV-2 negative. ${ }^{2}$

\section{Three Options for Infant Feeding}

We constructed three options ( - Table 1 ) with three principles in mind: (1) benefits of breastfeeding balanced against the risk of transmission of SARS-CoV-2 to infant, (2) disadvantages and advantages to be made known to mother and $\mathrm{HCP}$, and (3) mother and HCP need support and guidance to execute the option that they prefer. 
Table 2 Infection prevention and control practices for breastfeeding and infant feeding in COVID-19

\begin{tabular}{|c|c|}
\hline Scenarios & Recommendations \\
\hline $\begin{array}{l}\text { Mother infant } \\
\text { contact at birth }\end{array}$ & $\begin{array}{l}\text { - Mother should not be separated from her infant unless she is too sick to care for her infant (WHO, 2020) } \\
\text { - Enable rooming in and early skin-to-skin contact (WHO, 2020) } \\
\text { - Breastfeed within } 1 \text { hour of birth with appropriate Infection Prevention and Control (IPC) practices (WHO, 2020) }\end{array}$ \\
\hline $\begin{array}{l}\text { Direct } \\
\text { breastfeeding }\end{array}$ & $\begin{array}{l}\text { - Mothers are to wear face masks and perform respiratory hygiene (cough/sneeze into tissue and dispose, then } \\
\text { perform hand hygiene immediately; WHO, 2020) } \\
\text { - Wash hands before contact with infant, before and after each feeding (WHO, 2020) } \\
\text { - Clean chest with soap and water if coughing on it before breastfeeding (WHO, 2020) } \\
\text { - Clean and disinfect surfaces which the mother has been in contact with (WHO, 2020) } \\
\text { - Avoid coughing or sneezing on the infant while feeding (Royal College of Obstetricians and Gynaecologists, 2020) }\end{array}$ \\
\hline $\begin{array}{l}\text { Expression of } \\
\text { human milk }\end{array}$ & $\begin{array}{l}\text { - Mother encouraged and supported to express milk with appropriate IPC measures (WHO, 2020) } \\
\text { - Provide dedicated breast pump (Academy of Breastfeeding Medicine, 2020; CDC, 2020) } \\
\text { - Mothers to wear masks during the process (Marinelli \& Lawrence, 2020; WHO, 2020) } \\
\text { - Wash hands before touching pump or bottle parts and before expressing human milk (Academy of Breastfeeding } \\
\text { Medicine, 2020; CDC, 2020) } \\
\text { - Follow recommendations for proper pump cleaning before or after each use (Academy of Breastfeeding Medicine, } \\
\text { 2020; CDC, 2020) }\end{array}$ \\
\hline $\begin{array}{l}\text { Feeding of } \\
\text { expressed } \\
\text { human milk }\end{array}$ & $\begin{array}{l}\text { - Handle human milk containers with gloves (Marinelli and Lawrence, 2020) } \\
\text { - Consider disinfecting expressed human milk containers with virucidal agents } \\
\text { (CDC, 2020; Marinelli and Lawrence, 2020) } \\
\text { - If possible, have someone well to feed expressed human milk to infant (CDC, 2020) }\end{array}$ \\
\hline $\begin{array}{l}\text { Alternative milk } \\
\text { if mother's milk } \\
\text { is not available }\end{array}$ & $\begin{array}{l}\text { - Donor human milk as first choice (WHO, 2020) } \\
\text { - Wet nursing, appropriate human milk substitutes as alternatives (WHO, 2020) }\end{array}$ \\
\hline
\end{tabular}

Abbreviations: ABM, Academy of Breastfeeding Medicine; CDC, Centres for Disease Control and Prevention; CovID-19, novel coronavirus disease 2019; WHO, World Health Organization.

In all three options, a joint decision is made by HCP and parents. Some factors to consider include the clinical condition of mother and infant, viral test results of mother and infant, mother's preference about breastfeeding and the availability of facility and resources for isolation..$^{39}$ Lactation support needs to be available for mother whether she chooses to or not to breastfeed to preserve continued lactation. A major focus needs to be in instructing and counseling mother on IPC measures to avoid spreading the virus to her infant (hand hygiene, breast hygiene, proper use of face masks, hygienic measures to express milk, etc.) which is also practiced by HCP as shown in $=$ Table 2 .

We conclude, based on factors outlined above, option A is the most preferred option that can be implemented safely in most situations involving COVID-19 pregnancies. Options B and $\mathrm{C}$, if implemented for the wrong reasons, will add unnecessary strain to the health care organization and may jeopardize success of breastfeeding. These options proposed herein are not fixed once a decision is made and can be altered and adapted when situation changes. It is important to protect breastfeeding as advocated in baby friendly hospital practices ${ }^{7}$ and to limit interruptions to general care of mother and baby during the COVID-19 pandemic.

\section{Counseling Mothers with COVID-19 Infection for Breastfeeding}

Successful execution of option-based strategy requires proper guidance, counseling, and breastfeeding education to the mother. The following steps are based on established counseling principles for breastfeeding with necessary modifications applied to COVID-19. ${ }^{40-43}$ The processes below refer to the mother, but this approach can be modified to include her partner.

Counseling may be done through teleconversation, videoconference, or face-to-face encounter with personal protective equipment (PPE) precautions. The first meeting is ideally done before baby's birth, once mother has been diagnosed with COVID-19. However, with the widespread range of COVID-19 presentations, HCP may be confronted with various scenarios, ranging from a mother with confirmed, probable, suspect, presymptomatic infection or an asymptomatic carrier. There is even an emerging proposal for routine screening of obstetric patients admitted for labor, regardless of maternal symptomatology. ${ }^{44} \mathrm{HCP}$ should discuss with the mother options available to her, with an appropriate visual aid ( - Fig. 1) for her reference.

The counseling process involves the following five stages: (1) establishing a rapport, (2) gathering information, (3) defining the problem, (4) discussing possible solutions and (5) closing the contact by summarizing the decision making and possible follow-ups.

\section{Establishing a Rapport}

HCP first needs to establish a rapport with the mother to gain her trust. Acknowledge that the mother may have usual concerns of a new parent, and with added anxiety and fear about COVID-19. Carefully crafted questions (e.g., "You must be worried that you are diagnosed with COVID-19. What concerns you the most?") need to be asked with due sensitivity to clarify her situation and state of mind. 




Fig. 1 Infographic for counseling a mother with COVID-19 on breastfeeding. COVID-19, novel coronavirus disease 2019; HCP, health care provider.

\section{Gathering Information}

In the course of information gathering, HCP should remain supportive and start with open-ended questions before moving on to specific clarification questions. HCP may ask about mother's prior experience in breastfeeding and expectations, then proceed to specific COVID-19 questions: history of exposure, current state of illness, results of swab tests, knowledge about COVID-19, and breastfeeding, and similar history for other household members. As these questions could be stressful to the mother, HCP should try to reframe the situation to help the mother see a negative (or abnormal) experience in a more positive (or normal) light. For example, the mother might say that it would be difficult to resume breastfeeding once she recovers from COVID-19. HCP could reframe the situation by saying that she can start breastfeeding after her recovery; meanwhile, she should preserve her milk supply by expressing.

\section{Defining the Problem and Discussing Solutions}

The problem needs to be defined before a solution can be reached. Both HCP and the mother should agree on what the problem is. For example: "you have told me that you do not know whether to breastfeed in the light of COVID-19. Let me provide you with three different options with pros and cons of each option, so that we can reach a common understanding." HCP should patiently explain the preparation the mother needs to arrange for each option and provide her with necessary guidance and support. HCP should advocate option A as the most pragmatic and baby friendly approach while providing options $\mathrm{B}$ and $\mathrm{C}$ as alternatives in specific situations.

\section{Closing the Contact}

HCP should close the contact by affirming and adhering to the mother's decision regarding her infant's feeding. HCP should emphasize that current information indicates that breastfeeding in COVID-19 is safe and beneficial to her infant, and yet new evidence may emerge in the future. HCP should guide the mother to credible sources of information, such as WHO, CDC, and national guidelines. HCP should set a specific date to revisit the mother and provide her with updated information and answer her queries.

\section{Training HCP on Breastfeeding in COVID-19 Mothers}

All levels of HCP involved in infant care and breastfeeding support need to have foundational knowledge in COVID-19 and breastfeeding. They need to be oriented to the various options (-Table 1 ) available to the mother with pros and cons of each option. A smaller group of HCP should be prepared to do more in-depth counseling. Training modules may be planned as videoconferencing session in light of COVID-19 pandemic restrictions on group gatherings. We 


\begin{tabular}{|c|c|c|c|}
\hline Domain & Content & Instructional methods & Duration \\
\hline Knowledge & $\begin{array}{l}\text { COVID-19 and breastfeeding } \\
\text { General principles of counseling } \\
\text { Options for infant feeding in COVID-19 }\end{array}$ & Didactic (online) & 1.5 hour \\
\hline Skills & $\begin{array}{l}\text { Personal protection } \\
\text { PPE } \\
\text { Safe handling of human milk } \\
\text { Videoconferencing techniques }\end{array}$ & $\begin{array}{l}\text { Demonstration } \\
\text { and practice }\end{array}$ & 1 hour \\
\hline $\begin{array}{l}\text { Skills and } \\
\text { attitude }\end{array}$ & $\begin{array}{l}\text { Counseling COVID-19 mothers on } \\
\text { Infection Prevention and Control Practice } \\
\text { Counseling on breastfeeding and } \\
\text { infant feeding options }\end{array}$ & $\begin{array}{l}\text { Role play } \\
\text { Feedback }\end{array}$ & 1.5 hour \\
\hline
\end{tabular}

Abbreviations: COVID-19, novel coronavirus disease 2019; HCP, health care providers; PPE, personal protective equipment.

Table 4 Framework for breastfeeding research in COVID-19

\begin{tabular}{|lll|}
\hline Priority & $\begin{array}{l}\text { Possible } \\
\text { study design }\end{array}$ & Examples of clinical questions \\
& Observational & -Does early skin-to-skin contact result in virus transmission from mother to her infant? \\
& & -Does home pasteurization of human milk inactivate SARS-CoV-2? \\
& & - Woes human milk contain viable SARS-CoV-2?
\end{tabular}

Abbreviations: COVID-19, novel coronavirus disease 2019; SARS-CoV-2, severe acute respiratory syndrome-coronavirus-2.

propose a 4-hour training course on breastfeeding in COVID19 (-Table 3).

\section{Future Research Questions}

In the presence of uncertainties and limited knowledge in COVID-19, there is an obligation to conduct research and generate answers to aid prudent decision making. ${ }^{45}$ Acknowledging that randomized control trial (RCT) is the "gold standard" in scientific enquiry in medicine, the need for actionable knowledge is so acute that now it is indefensible for the health care community to wait for RCT results before taking actions. Hence, there is an urgency and ethical responsibility to start research with potential to change practice. Therefore, we propose the following framework of research based on priorities (-Table 4).

Immediate researches are need based and have direct and immediate implications on patient care. Examples include observational studies using existing resources and manpower, which can be done quickly, and without much interference from bureaucracy.

Intermediate priority research should be planned in the next 6 to 8 months to conduct cohort-based studies or smallscale pilot trials. Examples of such research include assessing the effect of near universal recommendation for caesarean section deliveries in China following COVID-19 pregnancies, and psychological wellbeing of mother and infant following prolonged separation after birth.

Long-term research agenda requires meticulous planning, a larger budget, and more resources. These include RCT to evaluate interventions either at individual level or at community/hospital level, which would take 12 to 24 months of lead time and a further 2 to 3 years for data analysis and publication.

\section{Conclusion}

Our current knowledge and evidence about COVID-19 and breastfeeding is limited and evolving fast. Many health authorities have overwhelmingly recommended breastfeeding with added infection control precautions, while others are more restrictive. We propose an optimal safe and mother-andchild friendly practice for breastfeeding, with two other options based on various situations and through a shared decision with parents. This approach is flexible and nonprescriptive, incorporating counseling of parents using visual aids and training of HCP. We suggest a framework for future breastfeeding research in COVID-19 to obtain answers for better decision making.

\section{Funding}

None 
Conflict of Interest

None declared.

Acknowledgments

We thank Dr. Dimple Rajgor for her help with editing, formatting, and submission of the manuscript for publication.

\section{References}

1 John Hopkins University COVID-19 Dashboard by the Center for Systems Science and Engineering (CSSE) at Johns Hopkins UniversityAvailable at: https://coronavirus.jhu.edu/map.html. Accessed July 17, 2020

2 Chen D, Yang H, Cao Y, et al. Expert consensus for managing pregnant women and neonates born to mothers with suspected or confirmed novel coronavirus (COVID-19) infection. Int J Gynaecol Obstet 2020;149(02):130-136

3 Malaysia's Ministry of Health. Guidelines on management of coronavirus disease. 2019 (COVID 19) in neonates. Available at: http://moh. gov.my/moh/resources/Penerbitan/Garis\%20Panduan/COVID19/ Annex_31_Management_COVID_19_in_Neonates.pdf.Accessed April 11,2020

4 Wang SS, Zhou X, Lin XG, et al. Experience of clinical management for pregnant women and newborns with novel coronavirus pneumonia in tongji hospital, China. Curr Med Sci 2020;40(02): 285-289

5 American Academy of Pediatrics AAP updates guidance on newborns whose mothers have suspected or confirmed COVID-19. Available at: https://www.aappublications.org/news/2020/05/ 21/covid19newborn052120. Accessed June 3, 2020

6 World Health Organization; UNICEF Global strategy for infant and young child feeding. Available at: https://apps.who.int/iris/bitstream/handle/10665/42590/9241562218.pdf;jsessionid=AD0A 2B493593BC84602EDA9F0BE74DA7? sequence=1. Accessed April 11,2020

7 World Health Organization Implementation guidance: Protecting, promoting, and supporting breastfeeding in facilities providing maternity and newborn services: the revised baby-friendly hospital initiative. Available at: https://www.who.int/nutrition/publications/ infantfeeding/bfhi-implementation-2018.pdf. Accessed April 11, 2020

8 Cochrane Pregnancy and Childbirth COVID-19 Review of national clinical practice guidelines for key questions relating to the care of pregnant women and their babies. Available at: https://pregnancy.cochrane.org/sites/pregnancy.cochrane.-

org/files/public/uploads/covid_pcg_powerpoint_results_final_0. pdf. Accessed June 3, 2020

9 World Health Organization Clinical management of COVID-19: interim guidance, 27 May 2020. Available at: https://apps.who.int/iris/handle/10665/332196. Accessed June 1, 2020

10 Centers for Disease Control and Prevention Care for breastfeeding women: interim guidance on breastfeeding and breast milk feeds in the context of COVID-19. Available at: https://www.cdc.gov/coronavirus/2019-ncov/hcp/care-for-breastfeeding-women. html. Accessed 3 June, 2020

11 Centers for Disease Control and Prevention Evaluation and management considerations for neonates at risk for COVID-19. Available at: https://www.cdc.gov/coronavirus/2019-ncov/hcp/caring-fornewborns.html. Accessed June 3, 2020

12 Schwartz DA, Graham AL. Potential maternal and infant outcomes from (wuhan) coronavirus 2019-nCoV infecting pregnant women: lessons from SARS, MERS, and other human coronavirus infections. Viruses 2020;12(02):194

13 Lu R, Zhao X, Li J, et al. Genomic characterisation and epidemiology of 2019 novel coronavirus: implications for virus origins and receptor binding. Lancet 2020;395(10224):565-574
14 Darnell MER, Taylor DR. Evaluation of inactivation methods for severe acute respiratory syndrome coronavirus in noncellular blood products. Transfusion 2006;46(10):1770-1777

15 Kampf G, Todt D, Pfaender S, Steinmann E. Persistence of coronaviruses on inanimate surfaces and their inactivation with biocidal agents. J Hosp Infect 2020;104(03):246-251

16 Wei WE, Li Z, Chiew CJ, Yong SE, Toh MP, Lee VJ. Presymptomatic transmission of SARS-CoV-2 - Singapore, January 23-March 16, 2020. MMWR Morb Mortal Wkly Rep 2020;69(14):411-415

17 Academy of Medicine Singapore Position Statement from the National Centre for Infectious Diseases and the Chapter of Infectious Disease Physicians, Academy of Medicine, Singapore-23 May 2020. Available at: https://www.ams.edu.sg/view-pdf.aspx? file=media\%5C5556_fi_331. pdf\&ofile=Period + of + Infectivity + Position + Statement $+($ final $)+-$ 23-5-20+(logos).pdf. Accessed 3 June 2020

18 Lang GJ, Zhao H. Can SARS-CoV-2-infected women breastfeed after viral clearance? J Zhejiang Univ Sci B 2020;21(05):405-407

19 Kirtsman M, Diambomba Y, Poutanen SM, et al. Probable congenital SARS-CoV-2 infection in a neonate born to a woman with active SARS-CoV-2 infection. CMAJ 2020;192(24): E647-E650

20 Zamaniyan M, Ebadi A, Aghajanpoor Mir S, Rahmani Z, Haghshenas M, Azizi S. Preterm delivery in pregnant woman with critical COVID-19 pneumonia and vertical transmission. Prenat Diagn 2020 doi:. Doi: 10.1002/pd.5713

21 Goh XL, Low YF, Ng CH, Amin Z, Ng YPM. Incidence of SARS-CoV-2 vertical transmission: a meta-analysis. Arch Dis Child Fetal Neonatal Ed 2020 (e-pub ahead of print). doi:. Doi: 10.311136/ archdischild-312020-319791

22 Ferrazzi E, Frigerio L, Savasi V, et al. Vaginal delivery in SARS-CoV2 infected pregnant women in Northern Italy: a retrospective analysis. BJOG 2020 doi:. Doi: 10.1111/1471-0528.16278

23 Díaz CA, Maestro ML, Pumarega MTM, Antón BF, Alonso CP. First case of neonatal infection due to COVID 19 in Spain. An Pediatr (Engl Ed) 2020;92(04):237-238

24 Salvatori G, De Rose DU, Concato C, et al. Managing COVID-19positive maternal-infant dyads: an italian experience. Breastfeed Med 2020;15(05):347-348

25 Buonsenso D, Costa S, Sanguinetti M, et al. Neonatal late onset infection with severe acute respiratory syndrome coronavirus 2 . Am J Perinatol 2020;37(08):869-872

26 Wu Y, Liu C, Dong L, et al. Coronavirus disease 2019 among pregnant Chinese women: case series data on the safety of vaginal birth and breastfeeding. BJOG 2020;127(09):1109-1115

27 Dong L, Tian J, He S, et al. Possible vertical transmission of SARSCoV-2 from an infected mother to her newborn. JAMA 2020;323 (18):1846-1848

28 Li Y, Zhao R, Zheng S, et al. Lack of vertical transmission of severe acute respiratory syndrome coronavirus 2, China. Emerg Infect Dis 2020;26(06):1335-1336

29 Wang S, Guo L, Chen L, et al. A case report of neonatal COVID-19 infection in China. Clin Infect Dis 2020;71(15):853-857

30 Marinelli KA. International perspectives concerning donor milk banking during the SARS-CoV-2 (COVID-19) pandemic. J Hum Lact 2020;36(03):492-497

31 Davanzo R, Moro G, Sandri F, Agosti M, Moretti C, Mosca F. Breastfeeding and coronavirus disease-2019. Ad interim indications of the Italian Society of Neonatology endorsed by the Union of European Neonatal \& Perinatal Societies. Matern Child Nutr 2020;16(03):e13010PubMed

32 Robertson CA, Lowther SA, Birch T, et al. SARS and pregnancy: a case report. Emerg Infect Dis 2004;10(02):345-348

33 Maertens K, De Schutter S, Braeckman T, et al. Breastfeeding after maternal immunisation during pregnancy: providing immunological protection to the newborn: a review. Vaccine 2014;32(16): 1786-1792 
34 Schlaudecker EP, Steinhoff MC, Omer SB, et al. IgA and neutralizing antibodies to influenza a virus in human milk: a randomized trial of antenatal influenza immunization. PLoS One 2013;8(08):e70867

35 Gregory KE, Walker WA. Immunologic factors in human milk and disease prevention in the preterm infant. Curr Pediatr Rep 2013;1 (04):. Doi: 10.1007/s40124-40013-40028-2

36 Centers for Disease Control and Prevention Influenza (Flu). Available at: https://www.cdc.gov/breastfeeding/breastfeeding-special-circumstances/maternal-or-infant-illnesses/influenza.html. Accessed April 20, 2020

37 Ong SWX, Tan YK, Chia PY, et al. Air, surface environmental, and personal protective equipment contamination by severe acute respiratory syndrome coronavirus 2 (SARS-CoV-2) from a symptomatic patient. JAMA 2020;323(16):1610-1612

38 Marinelli KA, Lawrence RM. Safe handling of containers of expressed human milk in all settings during the SARS-CoV-2 (COVID-19) pandemic. J Hum Lact 2020;323(16):1610-1612 PubMed

39 Chandrasekharan P, Vento M, Trevisanuto D, et al. Neonatal resuscitation and postresuscitation care of infants born to moth- ers with suspected or confirmed SARS-CoV-2 infection. Am J Perinatol 2020;37(08):813-824

40 Ivey $\mathrm{AE}$, Ivey $\mathrm{MB}$, Zalaquett $\mathrm{CP}$. Intentional Interviewing and Counseling: Facilitating Client Development in a Multicultural Society. 5th ed Belmont, CA: Brooks Cole; 2013

41 King FS. Helping Mothers to Breastfeed. Revised ed Nairobi, Kenya: African Medical and Research Foundation; 1992

42 Lauwers J, Swisher A. Counseling the Nursing Mother: A Lactation Consultant's Guide. Jones \& Bartlett Publishers; 2015

43 Wellstart International Lactation management self study modules, Level 1. 4th ed.. Available at: https://www.wellstart.org/SelfStudy-Module.pdf. Accessed August 20, 2020

44 Vintzileos WS, Muscat J, Hoffmann E, et al. Screening all pregnant women admitted to labor and delivery for the virus responsible for COVID-19. Am J Obstet Gynecol 2020;9378 (20):30472-30475

45 Tannert C, Elvers H-D, Jandrig B. The ethics of uncertainty. In the light of possible dangers, research becomes a moral duty. EMBO Rep 2007;8(10):892-896 